\title{
Injection Sclerotherapy with 5\% Phenol in Almond Oil in the Treatment of Rectal Prolapse in Children: Our Experience
}

\author{
Md Mozammel Hoque ${ }^{1^{*}}$ \\ Alauddin Ahmed' \\ Alak Nandy ${ }^{2}$ \\ 'Department of Pediatric Surgery \\ Chattagram Maa-0-Shishu Hospital Medical College \\ Chittagong, Bangladesh. \\ ${ }^{2}$ Department of Anaesthesia \\ Chattagram Maa-0-Shishu Hospital Medical College \\ Chittagong, Bangladesh.
}

\begin{abstract}
Background: Rectal prolapse is a relatively common condition in children. A wide variety of sclerosing agents have been used in the treatment of rectal prolapse in children. We have used $5 \%$ phenol in almond oil in the treatment of rectal prolapse in our children. The aim of this study was to find out the outcome of injection sclerotherapy with 5\% phenol in almond oil in the treatment of rectal prolapse in children. Methods: From May 2009 to December 2016 a total of 186 patients with rectal prolapse were treated by injection sclerotherapy with 5\% phenol in almond oil. Of which males were 112 and females 74 . Age ranged from 1.5 years to 7 years. Initial management included assessment and correction of predisposing factors. If the rectal prolapse persisted or if the prolapse required repeated reduction, injection sclerotherapy was performed. Number of injections, recurrences, and complications were reviewed. Results: Out of 186 patients recurrence occurred in 12 patients, cured after second injection in 10 patients and 2 children needs Thiersch's stitch. Excessive oozing at the injection site was in 5 patients. Conclusion: Injection sclerotherapy with $5 \%$ phenol in almond oil is simple, safe and effective treatment of recurrent rectal prolapse after failure to conservative measures.
\end{abstract}

Key words: Rectal prolapse; Injection sclerotherap; 5\% phenol in almond oil.

\section{INTRODUCTION}

Rectal prolapse is defined as the protrusion of rectum through anus. There are two types of paediatric rectal prolapse. One is the intermittent self-limiting variety, which is more common, less pronounced, and responsive to conservative measures. The other variety recurs with every defaecation or straining and may require injection sclrotherapy or surgical treatment ${ }^{1-4}$. Rectal prolapsed usually affects children between 1-3 years of age, a time during which rectal mucosa is loosely attached to the underlying muscularis, and flattening of sacrum which predispose to prolapse. It is also the time of learning to develop continence ${ }^{5,6}$. The etiology of rectal prolapse in children are as follow: Idiopathic, Neurologic (Anal sphincter paralysis) Ectopiaviscae (Bladder extrophy) after anorectoplasty for imperforate anus, nutritional and cystic fibrosis ${ }^{7}$. Idiopathic rectal prolapse is usually seen in otherwise healthy children ${ }^{8}$. In our country it is not uncommon to see patients suffering from diarrhea having rectal prolapse. Malnourished children also frequently present with rectal prolapse of various intensity ${ }^{8}$. Many treatments have been used for persistent rectal prolapsed. Treatment includes resection and fixation, abdominal posterior rectopexy, abdominal or perineal bowel resection, transanal suture rectopexy, posterior saggital procedure, Thiersch suture and injection sclerotherapy. The trend in managing pediatric rectal prolapse has been moving away from extensive surgery. Injection sclerotherapy using various agents has been recommended by various investigators ${ }^{9-12}$. 


\section{MATERIALS AND METHODS}

From May 2009 to December 2016 a total of 186 patients with rectal prolapse were treated by Injection sclerotherapy with 5\% phenol in almond oil in the department of pediatric surgery, Chattagram Maa-O-Shishu Hosptal Medical College. Of which males were 112 and females 74. Age ranged from 1.5 years to 7 years. Initial management included assessment and correction of predisposing factors. If the rectal prolapse persisted or if the prolapse required repeated reduction, injection sclerotherapy was performed. Number of injections, recurrences, and complications were reviewed.

\section{Technique of Injection Sclerothepy}

The preparation for this day care surgery procedure usually consisted of a fleet enema administered before arrival to the hospital. The operation is performed under general anesthsia with the patient in lithotomy position. The buttocks and perineal area were prepared with povidone iodine solution. A blood set needle was mounted on $10 \mathrm{ml}$ disposable syringe. The sclerosent was injected in rectal submucosa through mucocutaneous junction under guidence of finger inserted into anal canal with this blood set needle. About $10 \mathrm{ml}$ of $5 \%$ phenol in almond oil ( $3 \mathrm{ml}$ in each site) was injected at 3 sites (2, 6,10 O'clock position) to avoid haemorroidal vessels. The procedure was carried out as a day case. Children were discharged home to continue their stool softeners, diet in high fibre and fluids, oral metrondajole and analgesics. All children were followedup in outpatient department 2 weeks after sclerotherapy. Subsequent follow-up was arranged after 3-6 months depending on symptoms.

\section{RESULTS}

Out of total 186 selected patients the male : female ratio is 1.5:1. Age ranged from 1.5 years to 7 years. The presenting symptoms were prolapsing mass in all, per rectal bleeding in 4, rectal prolapse with prolapsed rectal polyp in 4 patients. Possible predisposing factors identified including Constipation 86 (46\%) Diarrhea 74 (39\%) Malnutrition with failure to thrive 18 (10\%) Spina bifida 5 (2\%) Post operative patients of high variety anorectal malformations in $5(2 \%)$ patients and Bladder exstrophy in $3(1 \%)$ patients. The sclerosing agents that is $5 \%$ phenol in almond oil was injected in all 186 patients along with rectal polypectomy in 4 patients. Out of them 174 (93.5\%) patients cured with one injection and recurrecnce occur in 12 $(6.50 \%)$ patients. Ten patients were cured in $2^{\text {nd }}$ injection and 2 patients required Theirsch's suture. Excessive oozing at the injection site was seen in 5 patients which improved conservatively.

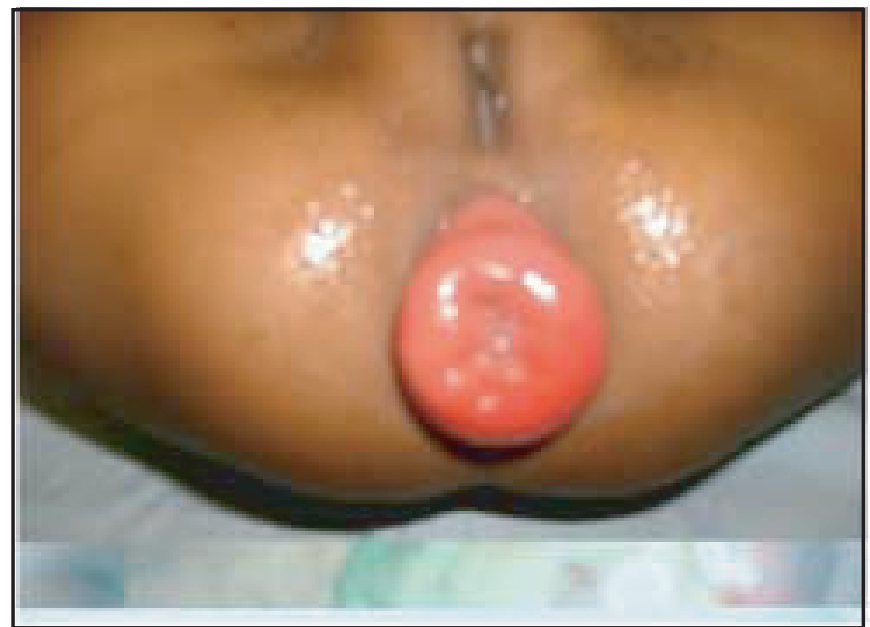

Figure 1 : Complete rectal prolapse.

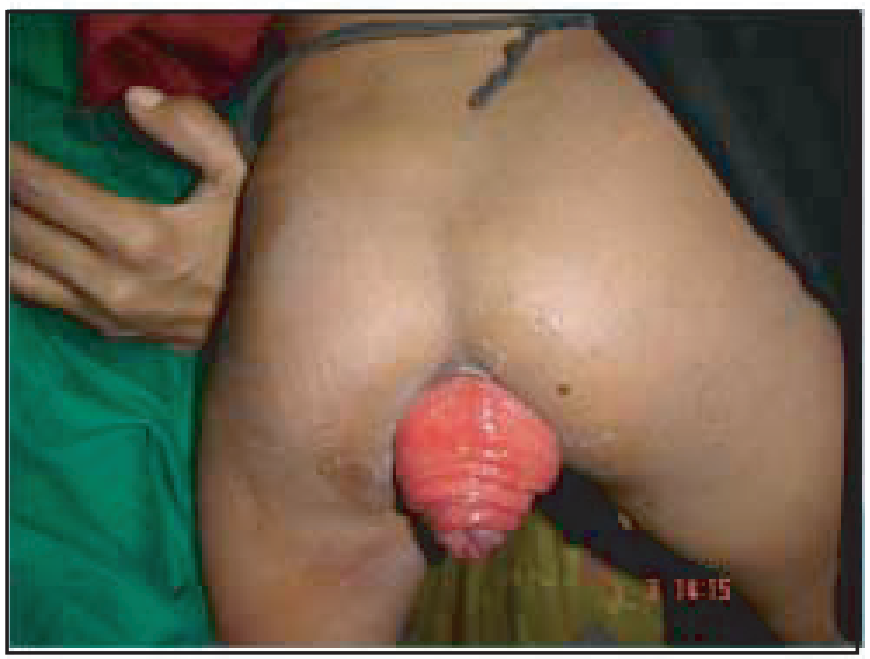

Figure 2 : Complete rectal prolapse.

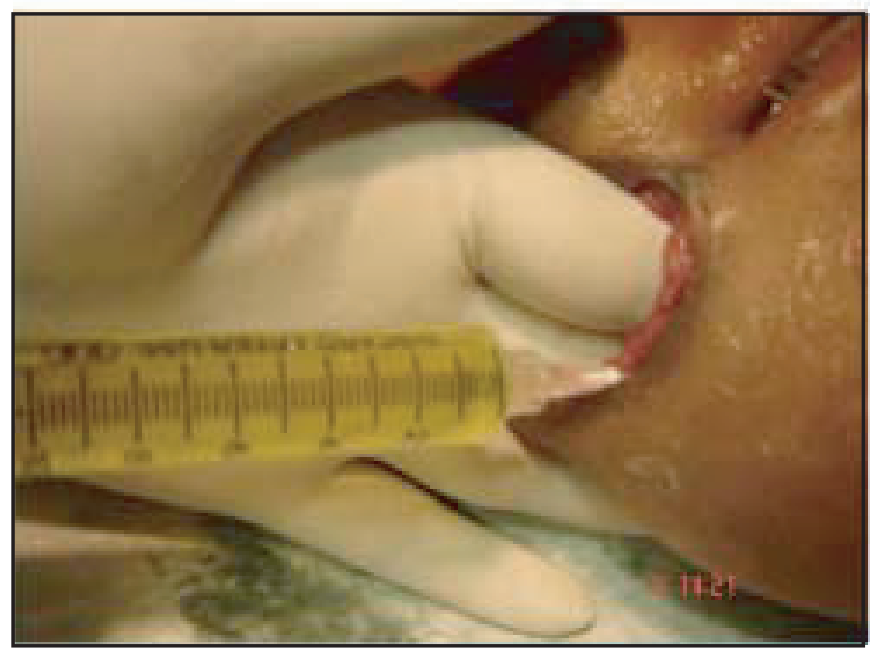

Figure 3: 5\% phenol in almond oil is injected submucosally through mucocutaneous junction. 


\section{DISCUSSION}

Rectal prolapse is a common problem in children in our country as well as in other developing countries. The majority of these cases are self limiting. Functional defaecation disorder and prolonged straining during defaecation in idiopathic constipation are noted to be frequent causes of prolapse rectum in children. It can also occur in diarrhea and in children with malnutrition. Mechanical factor such as sacral hypoplasia in bladder exstrophy and high anorectal anomaly may play a rule $^{12}$. Although there is no optimal or standerd procedure for treatment of rectal prolapse, initial treatment typically includes stool softeners, prevents straining during defaecation, treatment of diarrhoea and correction of malnutrition. If conservative treatment was not effective, various injection sclerosent agents such as $30 \%$ saline, cows milk, ethanolamine oleate, $30 \%$ ethylalcohol and 5\% phenol in almond oil should be considered as the first line treatment. In reviewing previous studies on injection sclerotherapy, it is apparent that many different agents can be used successfully and safely to treat rectal prolapsed.
We use only $5 \%$ phenol in almond oil as sclerosing agent in our patients. These initiates an inflammatory reaction resulting in fibrosis that gives support to the tissue thus prevents recurrence of the prolapsed. About $93.5 \%$ of our patients cured after one injection and $99 \%$ cured after two injections. Only 2 patients needs Thiersch stitch. Wyllie using 5\% phenol in almond oil as sclerosing agent, reported $91 \%$ cure rate after one injection, and $100 \%$ cure rate after two injections, almost similar to our results ${ }^{13}$. Only 5 patients had procedure related oozing at the injection site which improved conservatively.

\section{CONCLUSION}

Injection sclerotherapy with 5\% phenol in almond oil is inexpensive, easily available in our country. It is very safe and effective treatment for recurrent rectal prolapse after failure to conservative measures.

\section{DISCLOSURE}

All the authors declared no competing interest.

\section{REFERENCES}

1. Zgahjer M, Cizmic A, Cigit I, Zupancic B, Bumci I, Popvic L, et al. Treatment of rectal prolapse in children with cow milk injection sclerotherapy: 30 year experience. World J Gastroenterol. 2008;14:737-740.

2. Batool T, Akhtar J, Ahmed S. Management of idiopathic rectal prolapse in children. J Coll Physicians Surg Pak. 2005;15:628-630.

3. Gourgiotis S, Baratsis S, Buhr HJ. Rectal prolapse. Int J Colorectal Dis. 2007;22: 1561.

4. Groff DB, Nagaraj HS. Rectal prolapse in infants and children. Am J Surg. 1990; 160:531-532.

5. Chino ES, Thomas CG jr. Trans-sacral approach to repair of rectal prolapse in children. Am Surg. 1984;50:70-75.

6. Marvin L. Corman, Rectal Prolapse. Corman-Colon and rectal surgery, Lippincott Company. 1989; 2: 210.

7. S. W. Beasley. Acquired condition of the anorectum and perineum. Atwel Pediatric Surgery. Arnold Company. 1998; 1: 378.

8. Chan WK, Kay SM, Laberge JM, Gallucci JG, Bensoussan AL, Yazbeck S. Injection sclerotherapy in the treatment of rectal prolapse in infants and children. J Pediatr Surg. 1998; 33:255-258.

9. Tsugawa C, Matsumoto Y, Nishijima E, Muraji T, HigashimotoY. Posterior plication of the rectum for rectal prolapse in children. J Pediatr Surg. 1995; 30:692-693.

10. Reissman P, Weiss E, Teoh TA, Cohen SM, Wexner SD. Laparoscopic-assisted perineal rectosigmoidectomy for rectal prolapse. Surg Laparosc Endosc. 1995; 5:217-218.

11. Turell R. The Thiersch operation for rectal prolapse and anal incontinence. NY State J Med. 1954; 54:791-795.

12. Ashcraft KW, Garred JL, Holder TM, Amoury RA, Sharp RJ, Murphy JP. Rectal prolapse: 17-year experience with the posterior repair and suspension. J Pediatr Surg. 1990; 25:992-994.

13. Wyllie GG. The injection treatment of rectal prolapsed. J Pediatr Surg. 1979; 14:62-64. 